\title{
Preferred Learning Styles for Engineering Students
}

\author{
Sharon A. Driscoll, Carolyne E. Garcia \\ University of Arkansas
}

\begin{abstract}
The quest to improve effective teaching and student learning is on-going. Many different learning style models have been developed, but most are too complicated to give in interpret in the classroom. One simple tool that has been successfully used to gain insight into student learning is the VARK catalyst (Visual/Aural/Read-Write/Kinesthetic). Results obtained for class profiles of Freshmen and Junior level Chemical Engineering students using VARK indicate that student learning styles may differ substantially from what most professors believe and that these styles are firmly in place by the time a student reaches the university. Students showed much less preference for visual input than expected. The preferred learning style of the majority of students as was found to be kinesthetic (hands-on) mode, either by itself or in combination with other learning styles (multimodal). A discussion of the class results compared with activities designed to reach students through multiple modes proved easy to discuss with the students and opened up the discussion of study habits and active learning in the classroom.
\end{abstract}

\section{Introduction}

Although the roots of learning theory can be traced back to Descartes and Hobbes, the science of learning began with the work of Ivan Pavlov (1849-1936). Since then, numerous models of learning and retention have been proposed and studied. These researchers have found that, while the content of what is learned will change from case to case, the process of learning remains the same $^{1}$.

However, as educators attempted to apply these findings in the classroom they began to notice substantial differences in how students assimilate content. Further applied research demonstrated that students have preferred learning styles that directly impact the assimilation and retention of course content ${ }^{2-4}$.

This research resulted in the creation of a plethora of inventories to assess student learning styles. Smith ${ }^{5}$ identified 15 different instruments, and many more have been developed since ${ }^{6,7}$. Indeed, the Learning Style Assessment Profile kit ${ }^{8}$ contains 24 independent scales that "diagnose a student's cognitive style, as well as perceptual, affective, and environmental styles."

These instruments vary widely in their complexity, ease of administration, and the quality of information the results provide, both for teachers and students. Additionally, these instruments purport to measure different dimensions ${ }^{9}$, ranging from Harb's ${ }^{10}$ feeling/watching/thinking/ 
doing to Felder and Silverman' ${ }^{6}$ sensory-intuitive/visual-auditory/inductive-deductive/activereflective/sequential-global.

This has enormous implications for classroom teachers, who seek to optimize their teaching. How can a teacher be effective if everyone in the class acquires information in a different manner? How can a teacher even figure out what dimensions to assess, much less how to conduct the assessment. And, most important, how does this impact student learning.

Unfortunately, in higher education, most teachers are left to figure that out for themselves. As Patricia Cross ${ }^{11}$ notes, "teaching is in a primitive state of development ... related more to the characteristics and predilections of teachers than to the needs of the students." Pointing out that graduate schools do not provide students with any new information about teaching, she finds that most teachers still teach as they were taught, concluding that "graduate schools today are not turning out any better teachers that the graduate schools of 50 years ago."11

Left to struggle on their own, teachers have responded in a variety of ways. Some teachers just fall back on the ways that work for them. Some try various assessment tools with varying degrees of success. But even the best, most dedicated teachers may just throw up their hands and hope for the best. Fortunately, recent research has provided some enlightenment for engineering educators who are seeking to be more effective in the classroom and improve student learning.

Richard M. Felder, a Chemical Engineering professor at North Carolina State University, studied student learning styles in his classroom. In addition to the article provided for reference ${ }^{6}$, he has developed a web page "Richard Felder's Resourses in Science and Engineering Education" at www2.ncsu.edu/unity/lockers/users/f/felder/public/RMF.html with more information on his publications and views on active learning and learning styles. He has categorized learning styles by five different "dimensions" and corresponding continuum of student preference for processing of information: perception (sensing/intuitive), input modality (visual/verbal), organization (induction/deduction), processing (sequential/global), and understanding (active/reflective). According to Felder, visual input includes things like pictures, diagrams, flow charts and demonstrations. Verbal input includes both written and spoken words. If material is presented in the mode preferred by the student, it is thought to be more effectively processed by the brain and so better understood. Felder indicates that most students and faculty prefer visual input. Unfortunately, most engineering classes are still presented in lecture format, which is based on verbal information.

In 1992, Fleming and Mills ${ }^{7}$ published the results of their classroom research, which was based on the VARK catalyst. In Felder's terms, the VARK assesses input/modality, which is the student's preferred style for receiving information. However, rather than characterizing the input modes as a continuum from visual to verbal, as presented by Felder, the VARK catalyst examines the preference for each of four different input modes individually and allows preference for more than one input mode. The VARK catalyst and discussion of active learning and learning styles are available from Dr. Charles Bonwell ${ }^{11}$ over the internet at www.activelearning-site.com. 
Like Felder, Fleming and Mills found that students will learn material more effectively if they receive that information in the manner in which they prefer to receive information. The VARK catalyst divides input modes into four areas: ${ }^{7}$ visual (V), aural (A), read/write (R), and kinesthetic $(\mathrm{K})$. Visual learners prefer pictures, diagrams, and flowcharts. An aural learner indicates a preference for spoken words, while a read/write learner would prefer them written down. Kinesthetic learners can include information from other modes, but prefer experience -simulated or real -- and would include demonstrations, real life examples, and practice situations.

Fleming and Mills characterized the VARK as a tool for discussion and reflection. ${ }^{7}$ Not only can instructors benefit from this assessment tool by 1) examining their teaching styles and learning to present information more effectively and 2) developing teaching strategies to cover each different mode of input. Students can also benefit from using the VARK by learning about their own preferred input modes. This allows them to be more effective learners in all courses because they can adjust their study habits and the way they take and make notes to accommodate their modality preferences. The VARK can also be given to a class to indicate to the students and the instructor how they prefer to be given information as individuals and as a class. The results obtained from profiling of junior level and freshman level chemical engineering students at the University of Arkansas have provided some interesting insight into the preferred input mode for chemical engineering students. This paper discusses these results.

\section{History}

Beginning instructors are often disconcerted by how by how little information students actually process from a given class. In some cases, a student may ask a question related to material that has just been covered in class - with the answer still written on the chalkboard. Another student may ask a question related to information presented verbally but not written down. A third student may appear to pay no attention and take few notes, but when asked a question by the instructor will have a good answer immediately. In the past, Dr. Driscoll would verbally summarize the topic of the information to be covered, provide the theory, followed by specific examples. She would often be interrupted by students while covering theory with the question "why do we need to learn this." Since the train of thought was then interrupted, a quick verbal summary of examples to be used later was given before continuing with the theory.

The instructor's problems are often exacerbated by asking for input from students. For example, when asking for student feedback during the semester, Dr. Driscoll typically received the response "include more worked examples." Since at least one complete example per equation was always included in the discussion, she found this confusing, especially when students appeared to pay little attention during the worked example.

However, a significant clue toward solving the problem was provided a student, who commented, "I want to see you work out the problem so I know more about the thought process." She determined that the manner in which the examples were worked in class had a significant impact on whether or not the students really learned from the experience. When Dr. Driscoll started getting the students involved by predicting trends, guessing answers, and 
supplying calculated values, significantly more learning took place for the same number of examples! In searching for clues to what was happening in her classroom, Dr. Driscoll tried many assessment tools, including the VARK.

\section{Discussion of Results}

When the VARK catalyst was first used to profile a class, the results were unexpected. The profile for sixteen students taking the junior level Mass Transport class are presented in Table 1. Although previous research by Felder ${ }^{6}$ indicated a strong preference for visual learning among engineering students, these results show something different. The majority in this class (69\%) were multimodal. The strongest overall modality, combining pure and multimodal students, was kinesthetic (81\%). There were no pure visual learners, and visual input was a preferred modes of input for only $27 \%$ (3/11) of the multimodal learners. The high aural preference as part of the multimodal distribution (7/11) was also significant for this class. The profile was given the first day of class and the results were compiled anonymously.

The results of the profile were discussed with the class, and resulted in the continued change in teaching style toward a more interactive classroom. Student involvement in problem solving of examples during lecture was increased, and more time was devoted to group-based or pairs inclass problem solving by the students. This allowed students to solve more problems in a handson manner, and talk with each other while they worked. Dr. Driscoll went from group to group provide assistance, and help them one-on-one with specific questions. The majority of the students like this method, although in a few cases individuals worked on their own rather than participate.

Each Mass Transport class was profiled using the VARK catalyst over the next two semesters (spring and summer) essentially profiling the whole junior level class. These profiles showed some variation in results, but no drastic changes. Figures 1 and 2 summarize the combined results from all three semesters. Figure 1 shows the distribution among the different preferred input modes, grouping multi-modal learners together. Figure 2 presents the percentage contribution of each type of learning to the multi-mode numbers.

Overall, $81 \%$ of the students showed some type of preference for kinesthetic input, either as pure $\mathrm{K}$ or multi-modal kinesthetic learners. Twenty-two percent of the students indicated a pure kinesthetic learning style preference. Visual input as a preferred input mode was indicated for only $18 \%$ of the multimodal students, with no pure visual learners. The discussion in each class of their learning style profile, combined with the previous results, proved to be a good starting point for discussing the format for active learning activities. Positive feedback was given by the classes concerning the in-class problem solving and group work, and an improvement in examination scores was seen as compared with earlier classes. One student commented that even thought he knew he was a reflective learner, and might not understand everything during class, he liked this method of covering information.

For comparison with a different grade level, the instructor of the Fall 1999 freshman course "Introduction to Chemical Engineering" was asked to profile his class. The class was the largest in the last five years and so the sample was larger than the combined total of upper level students. Dr. Driscoll administered the VARK test and briefly discussed learning styles with the 
students. Because the class was $31 \%$ female, the students were also asked to indicate gender on the test. The overall results are summarized in Figures 3 and 4.

The percentage of pure kinesthetic learners was $36 \%$ as compared to $22 \%$ for the junior-level students. Higher numbers were also seen for the pure V, A, and R learning styles in the larger sample size. However, the distribution of preferred learning styles contributing to the multimodal learners was very similar to that found in the junior class. No significant differences were observed in comparing the male/female results.

It is interesting that the results presented here are so very different than the learning style preferences indicated by Felder and Silverman. ${ }^{6}$ There is a lack of preference for visual input modality by students, and when present it is generally combined with one or more additional modes. This might be a matter of definition rather than a true discrepancy. Felder and Silverman have defined the input modality dimension in such a way that demonstrations fall under the visual aspect. Thus, kinesthetic learners may fall partly under the banner of visual learning preference, while read/write and aural are together as verbal learners. If other aspects contributing to kinesthetic learning also qualify as visual preference, the VARK results would become a lot closer to data presented by Felder and Silverman. It may be that the differences in definition make a direct comparison impossible.

Little published data on VARK student profiles is available. Bonwell ${ }^{12}$ included some information concerning preferences that indicated wide variations in class profiles are possible for general education classes and fourth year/graduate students. Data from across the world suggest that most students are multimodal, and that the least preferred modality for students is aural. Thus, the first profile (Table 1.) shows a surprisingly high preference for aural input that was not anticipated according to available VARK data. This preference for aural input was moderated by additional class profiles, but remained consistently high while the visual component remained low.

Based on these results, some of the earlier feedback from students can be explained in terms of teaching and learning style mismatch. Chalkboard lectures and example problems written without discussion benefit read/write students, but leave out those with other learning preferences. Step-by-step discussion of the problem with student participation, or problem solving by students themselves benefits the aural and kinesthetic learners. Writing out the solution on the chalkboard as the process progresses will still be of benefit to pure read/write learners. An important aspect of kinesthetic learners is to start with the relevance of the importance to be presented. It was likely kinesthetic learners who asked questions during the theory presentation about possible applications. Lecture organization has since changed to start with a question related to an application: "what will happen when...? or how long does it take for ...?" with the question answered eventually using the appropriate equation.

Faculty learning preferences become important as in many cases. As previously mentioned, faculty tend to develop teaching styles related to their own learning style preferences. Little data from VARK is available concerning specific groups of faculty, but Bonwell ${ }^{12}$ presented some $^{2}$ information concerning faculty attending the conference on Excellence in Undergraduate Teaching. The faculty were found to be approximately equally divided between pure $\mathrm{R}$ and multi-modal, with few pure V, A, or K learners. No further breakdowns of the multimodal preferences were provided. Read/write teaching style is common. While all students can learn 
information presented on the chalkboard and from books, the information is not presented in the preferred input learning mode for the majority of the students.

The authors of this paper tested as pure K and RK. Interestingly, the instructor for the freshman course tested as VARK and so has no distinct preference for any particular learning style. This Professor has consistently received the high ratings from students and won the Catalyst Award for Teaching Excellence as well as University of Arkansas Burlington Outstanding Teacher Award and numerous other teaching awards. His multimodal learning preference may have helped him to develop an effective teaching style long before aspects of teaching and learning were a topic of investigation.

\section{Future work}

One potential use of the class profiles is to develop group assignments for problem solving with similar learning profiles. Many times allowing students to choose their partner in pairing situations students will result in similar characteristics - independent workers who wait until the end to compare answers, or students who talk through the problems together. Group interactions may also benefit from combining similar input preferences. This theory will be tested in spring 2000 and feedback requested from the students.

While our profiles appear different than the VARK data discussed by Bonwell ${ }^{12}$, it remained fairly consistent. One would suppose that within a given discipline, results should be consistent and may or may not follow general trends of other disciplines. It is possible that the preference for kinesthetic learning preference is a general characteristic of engineering, with possible differences in the distribution of other preferences for multimodal learners. This theory will be tested by evaluating students in different engineering departments prior to the 2000 ASEE conference.

This type of test may also be used in for retention and recruitment. Students often enter college with little knowledge of how to study through individualized methods. By continuing to use this exam in the freshman level class, the students are reached who can most benefit through this type of discussion, hopefully increasing retention. Also, knowing what type of student is attracted into chemical engineering can be used in developing a recruiting program. Including some type of hands-on activity and real equipment illustrating chemical engineering would be much more beneficial as compared to pictures of chemical plants or talking about chemical engineering.

\section{Conclusions}

The results of the VARK student profiles for chemical engineering juniors and freshmen indicates a strong preference for hands-on approach to learning. Undergraduate students in chemical engineering are mainly divided between pure kinesthetic learners and multimodal learners with a high preference for kinesthetic input. Because it is so strong in the class of incoming freshmen, it would seem that this preference for kinesthetic learning found in the majority of chemical engineering students is formed prior to entering college.

The incorporation of active learning activities into the mass transfer classroom proved extremely successful. VARK proved to be a good method for explaining this. Part of the explanation for 
this may be the abundance of kinesthetic learners that were not being reached at all by normal lecture or chalkboard teaching styles. Upon reflection, the successful active learning activities were those that reached multiple learning input modes.

VARK catalyst is a simple inventory that can be used to profile learning styles in a class. Both students and instructors can benefit from the results. Instructors benefit through a better understanding of their students and how to most effectively present information in the classroom. Modifying teaching styles to accommodate the results of the class learning style profile can improve student learning. The benefit to students involves both the discussion of learning styles and the modification of classroom activities to better reach all preferred input modes.

Bibliography

1. Schwartz, B. \& Reisenberg, D. Learning and memory. New York: Norton and Company (1991).

2. Claxton, C.S. \& Ralston, YLearning styles: Their impact on teaching and administration. ASHE Research Report No. 10, Washington, D.C.: Association for the Study of Higher Education (1978).

3. Price, G. Diagnosing learning styles. In R. M. Smith (Ed.) Helping adults learn how to learn. New Directions for Continuing Education. San Francisco: Jossey-Bass (1983).

4. Grasha, A.F. Using traditional versus naturalistic approaches to assessing learning styles in college teaching. Journal of Excellence in College Teaching, 23-38 (1990).

5. Smith, R.M. Learning how to learn. Chicago:Follett. (1982).

6. Felder, R.M. \& Silverman, L.K. Learning and teaching styles in engineering education. Engineering Education, 78(7), 674-681 (1988).

7. Fleming, N.D. \& Mills, C., Not another inventory, rather a catalyst for reflection. To Improve the Academy, 11(7), 137-155 (1992).

8. NASSP. Learning style instruction and the NASSP learning style profile. $h t t p: / /$ nassp.org/publications/learnstyles/ (September 1999).

9. Dunn, R., DeBello, T., Brennan, P., Krimsky, J. \& Murrain, P. Learning style researchers define differences differently. Educational Leadership. 372-375 (February, 1981).

10. Harb, J.N. and Terry, R.E. Application of the Kolb learning cycle to design instruction. Presented at the ASEE Rocky Mountain Section Meeting, Golden, Colorado, April 6, 1990.

11. Cross, P. Effective college teaching. ASEE Prism, (October, 1991) 27-29 (1991).

12. Bonwell, C.C., "Active learning and learning styles: making the connection". University of Arkansas Faculty Development Workshop, Mountain View, Arkansas. (1998).

SHARON A. DRISCOLL

Sharon Driscoll is an Assistant Professor of Chemical Engineering at the University of Arkansas. She also serves as Faculty Advisor for the Society of Women Engineers. Dr. Driscoll is a registered Professional Engineer in Arkansas. Dr. Driscoll received a B.S. degree (1984) in Chemical Engineering from the University of Washington in Seattle, and an M.S. (1989) and Ph.D. (1993) from The Ohio State University in Columbus.

CAROLYNE E. GARCIA

Carolyne E. Garcia is a Science and Research Communication Officer in the Office of University Relations at the University of Arkansas, Fayetteville. She specializes in engineering and business issues of local, national, and international significance. Prior to this, she taught for 12 years in the Department of Chemical Engineering at the U of A and served as Senior Technical Editor for the Society of Petroleum Engineers. She holds degrees in biology, business administration, petroleum engineering, and communication. 
Table 1. Semester Class Learning Profile for Junior Level Students

\begin{tabular}{|c|c|}
\hline Mode & $N$ (total = 16) \\
\hline V & 0 \\
\hline$A$ & 0 \\
\hline$R$ & 2 \\
\hline$K$ & 3 \\
\hline MM & $(11$ total) \\
\hline VR & 1 \\
\hline VRK & 1 \\
\hline VARK & 1 \\
\hline AK & 5 \\
\hline ARK & 1 \\
\hline RK & 2 \\
\hline
\end{tabular}

7
0
0
$\mathbb{0}$
0
0
0
0
$+\infty$
$\infty$ 


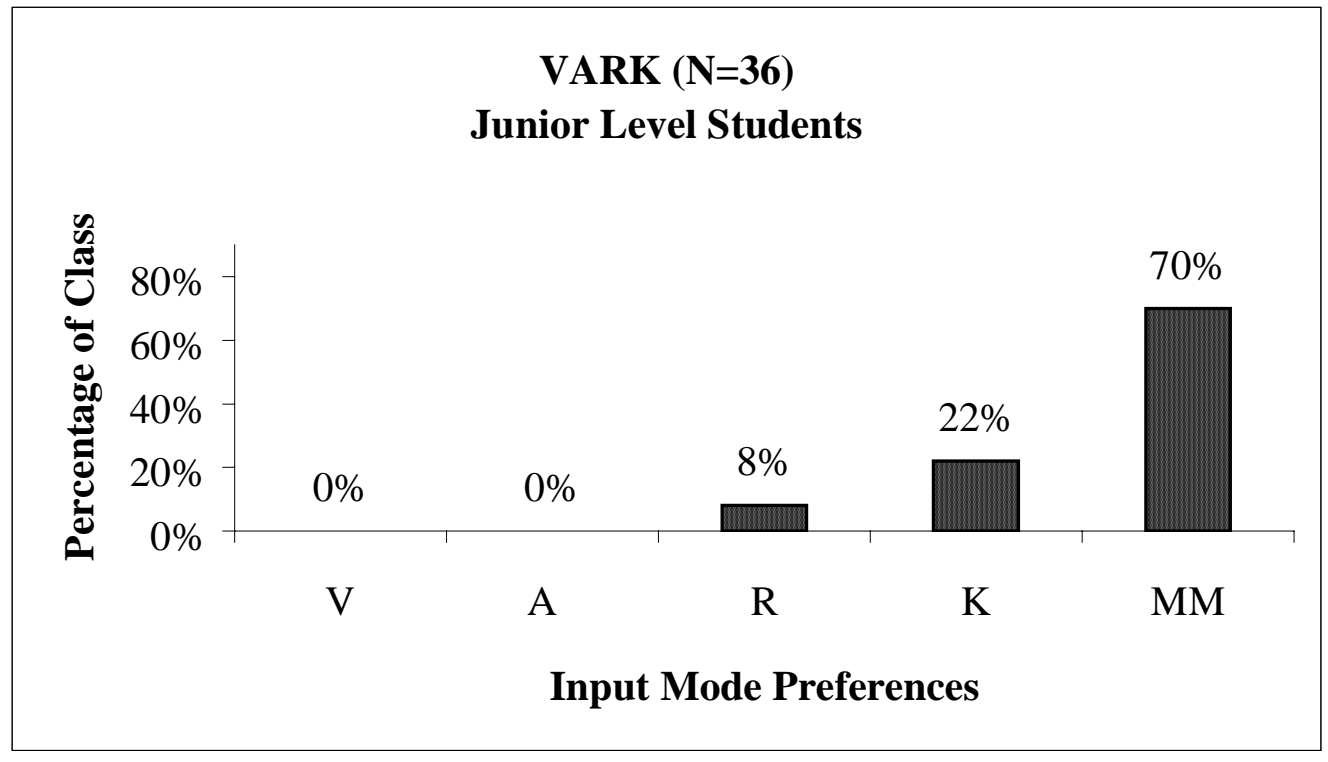

Figure 1. Learning Style Preference Distribution for Mass Transfer Students

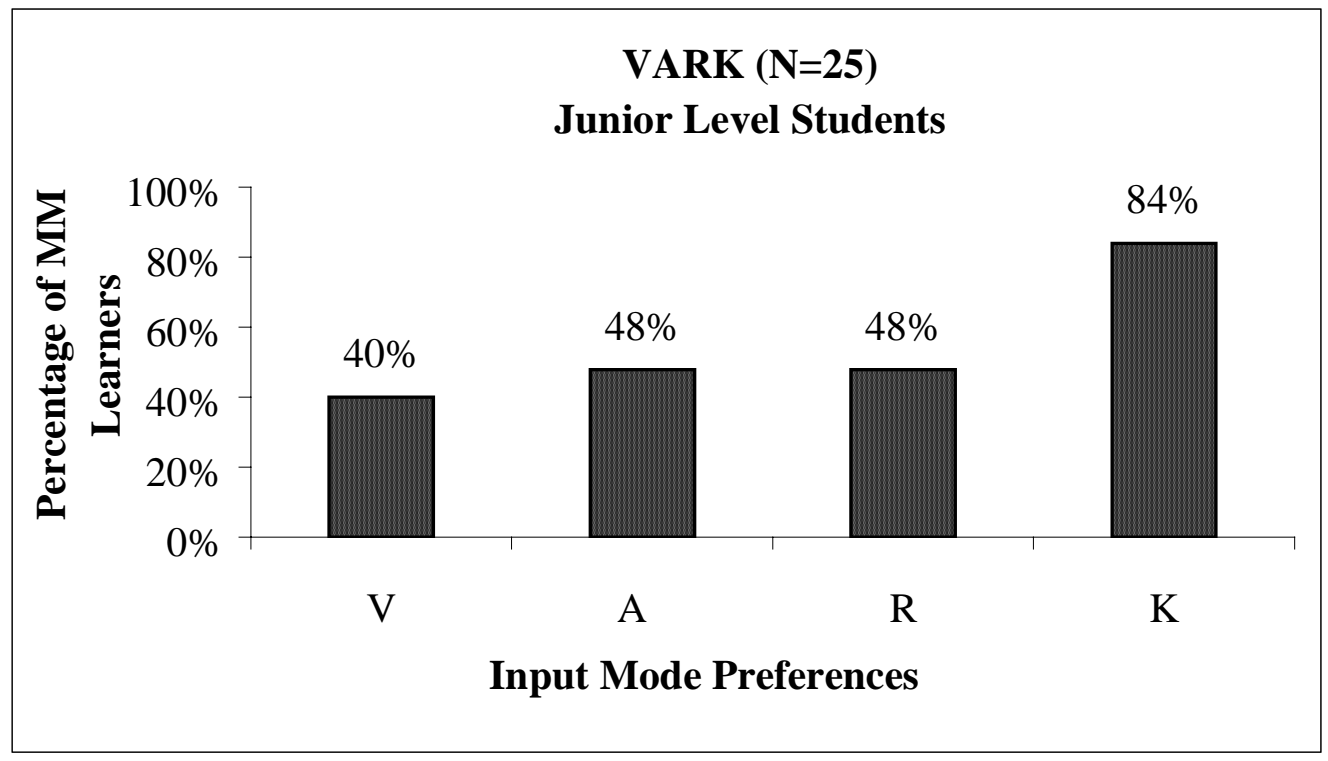

Figure 2. Multimodal Learning Style Preference Distribution for Mass Transfer Students 


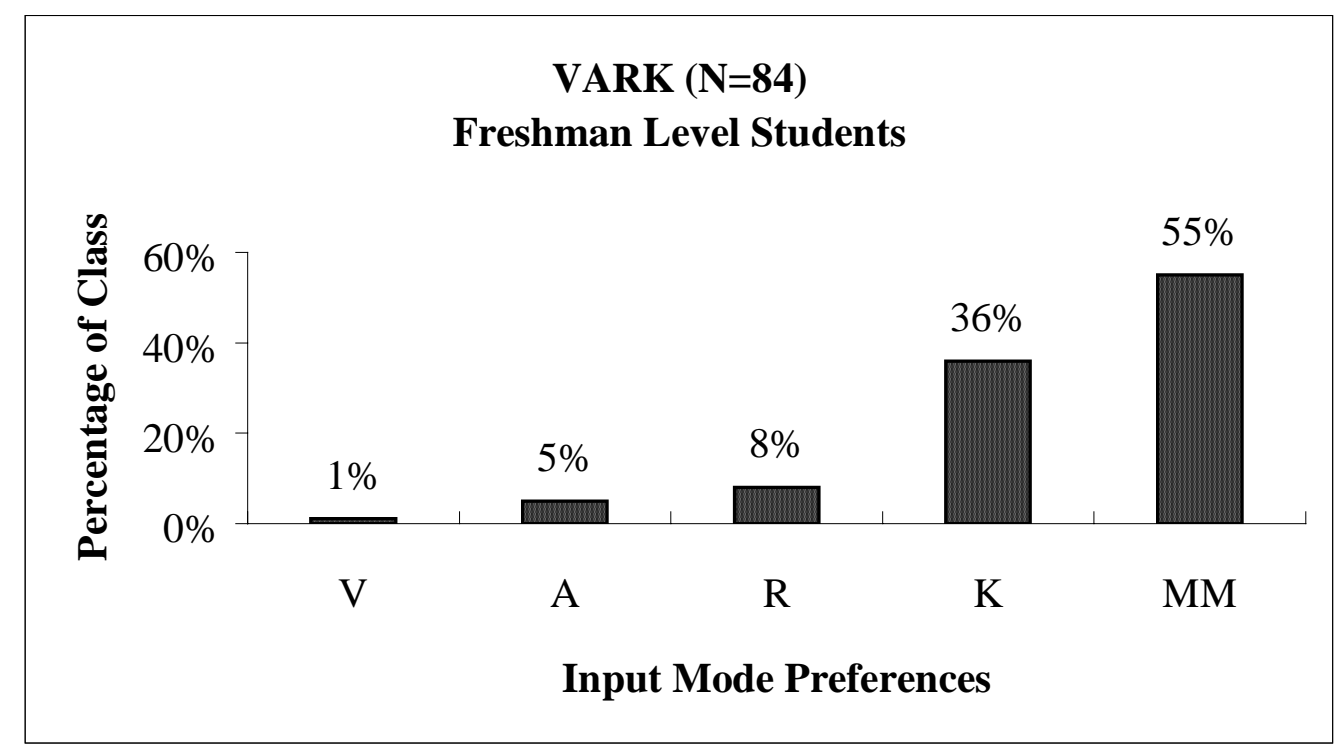

Figure 3. Learning Style Preference Distribution for Introduction to Chemical Engineering Students.

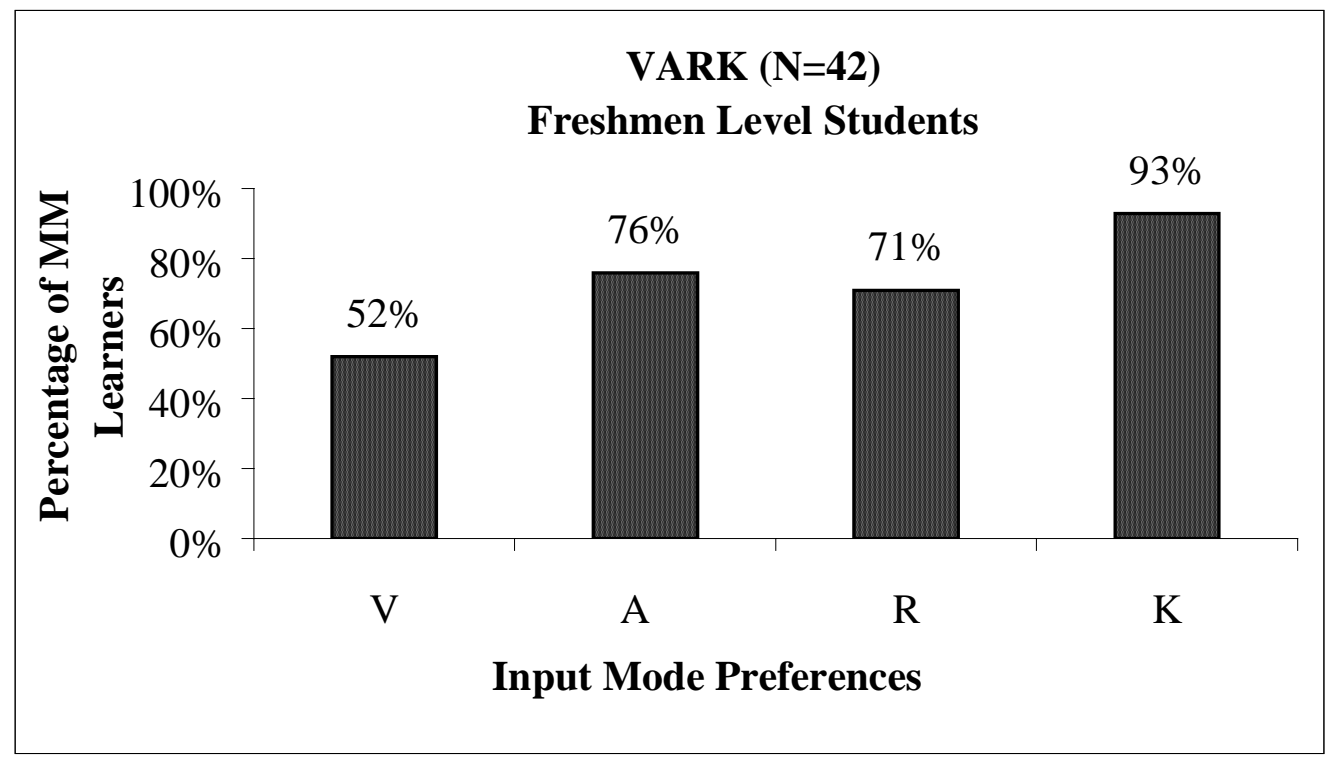

Figure 4. Multimodal Learning Style Preference Distribution for Introduction to Chemical Engineering Students. 